\title{
Adherence to physical activity recommendations and its associated factors: an interregional population-based study
}

\author{
Ala'a Alkerwi, ${ }^{1}$ Barbara Schuh,, ${ }^{1,2}$ Nicolas Sauvageot, ${ }^{1}$ Faiez Zannad, ${ }^{3}$ Arnaud Olivier, ${ }^{3}$ \\ Michèle Guillaume, ${ }^{4}$ Adelin Albert, ${ }^{4}$ Charlotte A. Larsson, ${ }^{2}$ on behalf of NESCaV project \\ group \\ ${ }^{1}$ Luxembourg Institute of Health L.I.H., Strassen; ${ }^{2}$ Division of Social Medicine and Global Health, \\ Department of Clinical Sciences, Malmö, Lund University, Sweden; ${ }^{3}$ Département des Maladies \\ cardiovasculaires, Hypertension Unit, Centre Hospitalier Universitaire, Nancy, France; \\ ${ }^{4}$ Department of Public Health, University of Liège, Belgium
}

\begin{abstract}
Significance for public health
This manuscript describes the prevalence of physical activity level of adult population from three European regions, Luxembourg, Wallonia and Lorraine, based on the adherence to the WHO physical activity recommendations. It identifies the potential demographic, socioeconomic, perceptive and behavioural factors associated with meeting physical activity recommendations. This study hence has a significant public health interest; as it constitutes a first step to help decision-makers and health authorities to target atrisk populations and to guide the development of preventive programs. Preventing physical inactivity in the Greater Region, the fourth leading cause of mortality, can reduce cardiovascular disease burden and substantially improve overall health of a big segment of the European population.
\end{abstract}

\section{Abstract}

Background. Though the influence of physical activity in preventing cardiovascular diseases is well documented, only a few comparative studies have determined the degree of adherence to physical activity recommendations among populations and identified the demographic, socioeconomic, behavioural and health-related factors associated with good compliance.

Design and methods. Cross-sectional interregional NESCaV survey of 3133 subjects compared three populations, Luxembourg, Lorraine (France) and Wallonia (Belgium), by using the International Physical Activity Questionnaire. Age and gender prevalence rates of physical activity were standardized to the European population.

Results. The likelihood to meet the recommendations was higher in Luxembourg, after adjustment for age, gender, education, employment, weight status, morbidity score, health perception and level of importance attributed to the practice of physical activity $(\mathrm{P}<0.0001)$. The odds for meeting the recommendations were significantly higher among those with secondary than tertiary education. Compared to good self-health perception, subjects with poor or fair self-perceived health were less likely to meet the recommendations; this also applied to those attributing little or enough importance to physical activity compared with great importance.

Conclusions. Region, education, self-perceived health and perception of importance of physical activity were emerged as independent determinants of meeting the recommendations. Awareness of the positive health effects of physical activity might thus be crucial for motivating the people to become more active. Further research is needed to explore potential region-specific factors which might explain the difference in population behaviours with respect to physical activity.

\section{Introduction}

There is now overwhelming evidence that regular physical activity has extensive health benefits, which range from reduced risk of chronic diseases and some cancers to enhanced mental health, and improved quality of life..$^{1-4}$ Physical activity is related to health benefits in a linear dose-dependent manner, suggesting that every bit of exercise counts towards better health, with greater benefits at higher energy expenditures. ${ }^{5}$ In contrast, physical inactivity is associated with an increased risk for multiple causes of mortality, chronic morbidity and disability. ${ }^{6}$ In high income countries, physical inactivity is the fourth leading risk factor for mortality, causing an estimated 3.2 million deaths globally. ${ }^{7}$ This potentially modifiable unhealthy lifestyle has been directly linked to cardiovascular risk factors, including arterial hypertension, hypercholesterolemia, hyperglycaemia, overweight and obesity. ${ }^{8}$

Over the past decade, increasing physical activity level has become a public health concern that led to publication of many national and international recommendations. The World Health Organization (WHO) recommends a minimum 30 minutes of physical activity of moderate intensity on most days of the week, where activities should be performed for at least 10 minutes consecutively. ${ }^{7}$

Only a few European and international studies have determined the degree of adherence to current recommendations among general populations, and generally with inconsistent findings. ${ }^{9-12}$ The main reasons may be related to the heterogeneity of study designs, as well as to the conceptual differences in the assessment of physical activity. ${ }^{10}$

The European policies aim to stimulate interregional cooperation and promote social, economic and health development to overcome the discrepancies between the European populations. The so-called Greater Region, encompasses about 11.4 million people over an area of $65,400 \mathrm{~km}^{2}$. Despite the apparent cultural homogeneity of the population residing in the Greater Region, no scientific evidence supports this observation in terms of lifestyles, particularly practicing physical activity. NESCaV study (Nutrition, Environment and Cardiovascular Health) is a cross-border cardiovascular health monitoring project, including three neighbouring regions; Grand-Duchy of Luxembourg, Wallonia in Belgium, and Lorraine in France. It is the first cross-sectional, population-based survey carried out in the central zone of Europe, based on a standardised method of recruitment, and validated data collection tools, enabling a relevant inter-regional comparison, in terms of cardiovascular health and lifestyle-related risk factors. ${ }^{13}$

Based on the current state of knowledge, we hypothesized that interregional discrepancies with regards to practice of physical activity 
exist, which may be explained by several socio-economic and healthrelated behaviours and perceptions. The objectives of the present paper were to assess the physical activity level of adult population from three European regions, Luxembourg, Wallonia and Lorraine, based on the adherence to the WHO physical activity recommendations, and secondly, to identify potential demographic, socioeconomic, perceptive and behavioural factors associated with meeting physical activity recommendations.

This study has a significant public health interest; it constitutes a first step that may help decision-makers and health authorities to target at-risk populations and guide the development of preventive programs. Preventing physical inactivity in the Greater Region, the fourth leading cause of mortality, ${ }^{8}$ can reduce cardiovascular disease burden and substantially improve overall health of a big segment of the European population.

\section{Design and Methods}

\section{Study population}

We calculated that in each of the regional surveys, a minimal necessary representative sample of 1000 participants would provide regionspecific estimates with a statistical precision of at least $2 \%$ at the $95 \%$ confidence level, ${ }^{14}$ i.e., a total NESCaV sample of 3000 participants to ensure statistical power for examining the prevalence of various cardiovascular risk factors of interest, including physical inactivity. Pregnancy and institutionalization were defined as exclusion criteria. A description of the study protocol has been detailed elsewhere. ${ }^{13}$ Briefly, a stratified random sample of 3133 subjects, aged 18-69 years, was recruited from the respective national registries of the adult population of Luxembourg, Lorraine and Wallonia, constituting an important segment of the Greater Region population. Data were collected between 2008 and 2012, over an average period of 12 months for each region, so that to reduce the effect of seasonal variation. The three populations (1432 subjects from Luxembourg, 1017 subjects from Wallonia and 684 subjects from Lorraine) were representative with regards to gender distribution, but older people were overrepresented in Luxembourg and Lorraine samples.

Subjects were invited via personal mail and a follow-up phone call to fix an appointment in one of the study centres. Participants were asked to fill out a questionnaire with the help of trained research nurses. The original French version of the questionnaire was translated into German, English and Portuguese, to incorporate the linguistic diversity of the population in Luxembourg. Validity was ensured through backward translation into French. At the study field, each participant received information on the aims of the study and the procedures of data collection.

Information was collected about age, gender, country of birth, marital status, educational level, employment status, and resource perception, smoking status, personal medical history and medication intake, self-perceived health, and the importance of physical activity on health. Blood pressure and anthropometric parameters were measured in addition to blood sampling. All were done according to standard operating procedures.

\section{Physical activity assessment}

Physical activity was determined using the International Physical Activity Questionnaire (IPAQ), tested for validity and reliability to measure the intensity, frequency and duration of physical activity during the preceding week before the interview. ${ }^{11,15,16}$ The IPAQ considers all domains of physical activity; at work, household, transport and leisure time physical activity. Total metabolic equivalent (MET- min/week) for vigorous-intense, moderate-intense and walking was calculated to categorise the studied populations into three levels: ${ }^{17}$ active, moderately active and inactive, in line with the IPAQ scoring criteria. ${ }^{18}$

\section{Compliance to physical activity recommendations}

The WHO recommends at least 150 minutes per week of moderateintense physical activity for adults, or accumulating a minimum 30 minutes of moderate intense physical activity on at least five days per week. ${ }^{19}$ According to IPAQ scoring criteria, a person who is physically active or moderately active was considered as a complier to the WHO physical activity recommendations.

\section{Covariates}

Body mass index (BMI) was calculated as body weight divided by height in meters squared $\left(\mathrm{kg} / \mathrm{m}^{2}\right)$ and classified in three categories according to WHO guidelines, ${ }^{20}$ i.e. normal weight $\left(<25 \mathrm{~kg} / \mathrm{m}^{2}\right)$, overweight $\left(25-29.9 \mathrm{~kg} / \mathrm{m}^{2}\right)$, and obese $\left(\geq 30 \mathrm{~kg} / \mathrm{m}^{2}\right)$. Education level, based on the highest diploma obtained, was classified into three groups: tertiary level equivalent to university or more; secondary level equivalent to classical or technical qualification; and primary level corresponding to non-academic qualification (but at least first 9 years of mandatory schooling). Resource perception was used as an indirect indicator for subjective economic status, which may help to overcome the crossregional discrepancy in terms of income. Subjects were asked to indicate how well their current income allows them to provide for their needs, i.e. very difficult, fairly difficult, fairly easy, or very easy. Due to few cases, the categories were regrouped into difficult and easy. Marital status was categorised as married/living with partner or living alone (including single, divorced and widowed). Smoking status was determined as current smoker, former smoker, occasional smoker, and never smoked. Morbidity was examined via a score composed of three important risk factors (hypertension, diabetes and dyslipidaemia). It ranged from 0 (absence) to 3 (presence of all three diseases). Self-perceived health was reported as very good, good, fair, poor and very poor, which was collapsed into 3 categories good, fair, and poor. The study also assessed the importance people attribute to physical activity on health; great, enough, little or no importance to participate in physical activities such as exercise, sports and games. Further covariates were gender, age (continuous), and the three regions.

\section{Ethical aspect}

Each subject gave signed written informed consent beforehand. The study was approved by the Comité National d'Ethique et de Recherche for Luxembourg, the Comité de Protection des Personnes Est-III for Lorraine, and the Comité d'Ethique Hospitalo-Facultaire Universitaire de Liège for Wallonia.

\section{Statistical analysis}

Initially, the participants' characteristics were compared by using the chi-square test. Then, the comparison of physical activity levels (low, moderate and high) across the three regions was plotted in a column chart. To ensure a meaningful interregional comparison between the three populations, with different age and gender composition, the direct standardization method was applied, using the European population as a reference. ${ }^{21}$

Univariate and multivariable logistic regression analyses, expressed as odds ratios with $95 \%$ confidence intervals (CI), were performed to identify factors significantly associated with the adherence to physical activity recommendations (dependent outcome variable). A set of potential predictor variables was selected, including age, gender, marital status, education level, region, subjective economic resources, smoking habits, BMI, morbidity, general health perception and partici- 
pant's awareness of the importance to participate in physical exercise. Young age women, married, with tertiary education, having easy resources perception, non-smokers, living in Luxembourg region, having normal weight status, having no cardiovascular disease (hypertension, diabetes or dyslipidaemia), having good health perception, and giving great importance to participation to physical activity exercises were considered as referent. Selection of the variables in the multivariable logistic regression model was based on literature review and on statistical criteria (variable showing $\mathrm{P}<0.10$ in the univariate analyses).

All tests were two-sided and statistical significance was determined when $\mathrm{P}<0.05$. Data were analysed using IBM SPSS Statistics for Windows, Version 20.0 (IBM Corp. Armonk, NY, USA).

\section{Results}

\section{Description of the Nutrition, Environment and Cardiovascular Health study population}

Table 1 displays the characteristics of the study participants. Luxembourg (1432 participants) represented the largest share of the study population, followed by Wallonia (1017 participants), and Lorraine (684 participants), constituting $45.7 \%, 32.5 \%$, and $21.8 \%$ of the total interregional sample, respectively. ${ }^{22-24}$ The distribution of gender was not significantly different across the three regions. However, participants from Lorraine were much older, as the 50-69 years age group constituted $75.5 \%$ compared to $34.1 \%$ in Luxembourg and $38.2 \%$ in Wallonia. The three samples differed significantly in terms of demographic, socio-economic, health status, lifestyle behaviours and health perception.

Considering the three regions together, the majority (54.9\%) were overweight or obese. Nearly $46 \%$ of them had at least one important risk factor (diabetes, hypertension or dyslipidaemia). Positively, more than half of the sampled populations were never smokers, though the smoking status was remarkably different between the three regions $(\mathrm{P}<0.0001)$. Most participants rated their health as good $(69.2 \%)$. Concerning the importance attributed to physical activity for health, $37.7 \%$ gave great importance and $44.5 \%$ enough importance.

About $77 \%$ of the studied subjects were conformed to physical activity recommendations, with a significantly higher adherence in Luxembourg (82\%) than in Lorraine (74\%) and Wallonia (71\%).

\section{Interregional comparison of physical activity levels}

Figure 1A displays the age and gender standardized prevalence of physical activity levels in the three regions. The distribution of physical activity levels differed substantially between the three regions, with lowest physical inactivity recorded in Luxembourg. While $54 \%$ of the subjects were physically active in Luxembourg, the majority (40\%) were moderately active in Lorraine. With respect to Wallonia, the proportions of active and moderately active people (34\%) were equal. For the three regions, there was gender-specific difference in the distribution of physical activity levels, observed in Luxembourg, where the proportion of inactive women were significantly higher than the men (Figure 1B).

\section{Factors related to adherence to physical activity recommendations}

Table 2 represents the demographic, socioeconomic, behavioural and health-related factors associated with meeting physical activity recommendations among the population of the Greater Region. ${ }^{22-24}$ In the univariate analyses, the adherence to physical activity recommendations differed significantly according to region $(\mathrm{P}<0.0001)$, age groups $(\mathrm{P}=0.033)$, education level $(\mathrm{P}<0.0001)$, employment status $(\mathrm{P}=0.003)$, weight status $(\mathrm{P}=0.033)$, self-perceived health $(\mathrm{P}<0.0001)$ and the importance agreed by the subjects to a regular practice of exercises and sports $(\mathrm{P}<0.0001)$.

In the adjusted model, region, education level, self-perceived health and importance of physical activity on health remained significantly related to meeting the recommendations. Subjects from Lorraine and Wallonia were less likely to meet the recommendations $(\mathrm{OR}=0.57 ; 95 \%$ CI: $0.42-0.74$ and $0 \mathrm{R}=0.50 ; 95 \% \mathrm{CI}$ : $0.40-0.63$ ) respectively compared to Luxembourg $(\mathrm{P}<0.0001)$. Subjects with secondary education were significantly more likely to meet the recommendations compared to those with tertiary education $(\mathrm{OR}=1.60 ; 95 \% \mathrm{CI}$ : $1.30-1.98)$. Although statistically borderline, obese subjects were less likely to meet physical activity recommendations, compared to normal weight subjects $(\mathrm{OR}=0.76$; 95\%CI: 0.58-1.00, $\mathrm{P}=0.054)$. Subjects self-reporting their health as fair or poor were less likely to meet the recommendations than those selfreporting their health as good $(\mathrm{OR}=0.74 ; 95 \% \mathrm{CI}$ : $0.59-0.92$ and $\mathrm{OR}=0.43 ; 95 \% \mathrm{CI}$ : $0.25-0.72$, respectively). Likewise, the odds for meeting the recommendations were significantly lower for subjects attributing little and enough importance to physical activity compared to great importance $(\mathrm{OR}=0.39 ; 95 \% \mathrm{CI}: 0.30-0.52$ and $\mathrm{OR}=0.57 ; 95 \% \mathrm{CI}: 0.46$ 0.71 , respectively).

\section{Discussion}

It is well documented that regular physical activity has substantial health benefits and reduces risk of many chronic diseases. Therefore, the current states' strategies support the WHO guidelines to formulate recommendations on the duration and intensity of health-enhanced

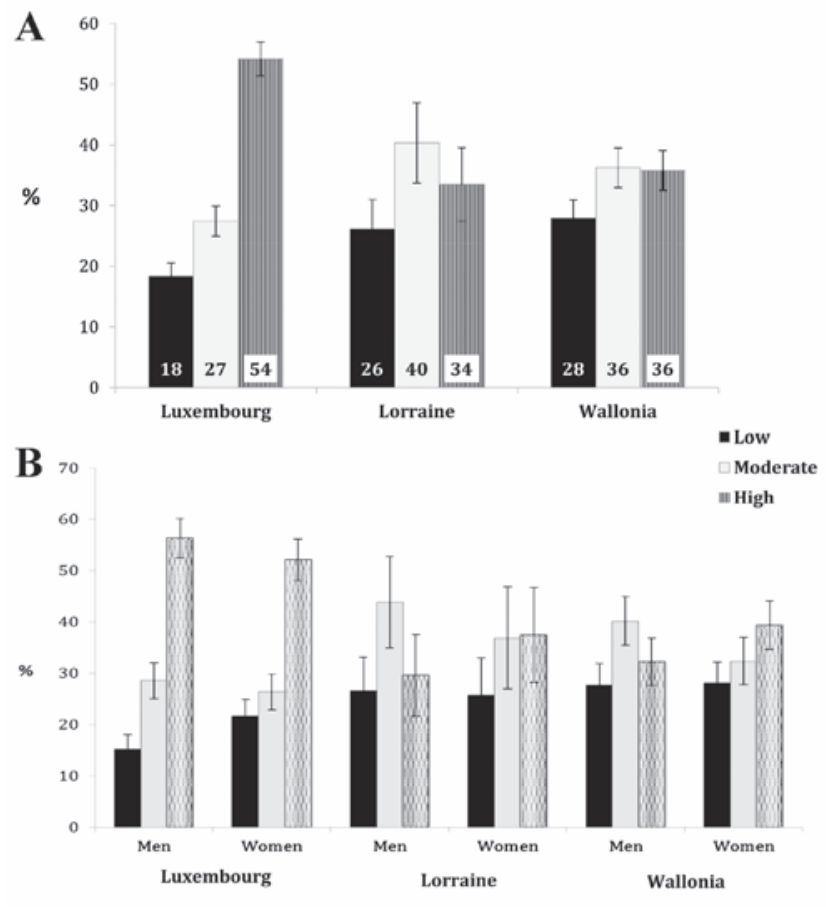

Figure 1. A) Prevalence of physical activity levels in Luxembourg, Lorraine and Wallonia; B) Gender-specific prevalence of physical activity levels in Luxembourg, Lorraine and Wallonia (age and gender standardised to the European population). 
Table 1. Characteristics of the Nutrition, Environment and Cardiovascular Health study population, 2007-2012.

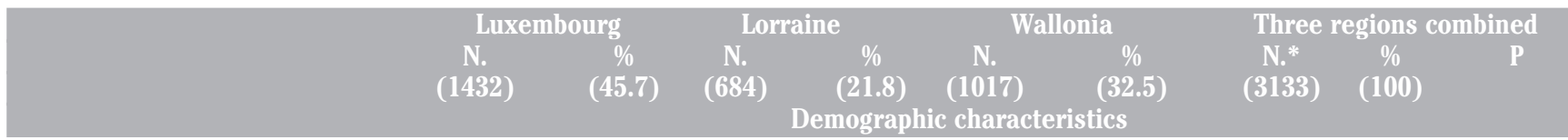

Age group, years

$\begin{array}{lcccccccc}\text { 18-29 } & 221 & 15.4 & 55 & 8.0 & 178 & 17.5 & 454 & 14.5 \\ 30-49 & 723 & 50.5 & 113 & 16.5 & 450 & 44.2 & 1286 & 41.2 \\ 50-69 & 488 & 34.1 & 516 & 75.5 & 389 & 38.2 & 1385 & 44.3 \\ \text { ender } & & & & & & & & \\ \text { Men } & 697 & 48.7 & 325 & 47.5 & 506 & 49.8 & 1522 & 48.7 \\ \text { Women } & 735 & 51.3 & 359 & 52.5 & 511 & 50.2 & 1603 & 51.3\end{array}$

\begin{tabular}{|c|c|c|c|c|c|c|c|c|c|}
\hline \multicolumn{10}{|c|}{ Socio-economic characteristics } \\
\hline $\begin{array}{l}\text { Education level } \\
\text { Primary } \\
\text { Secondary } \\
\text { Tertiary }\end{array}$ & $\begin{array}{l}380 \\
667 \\
371\end{array}$ & $\begin{array}{l}26.8 \\
47.0 \\
26.2\end{array}$ & $\begin{array}{c}38 \\
380 \\
250\end{array}$ & $\begin{array}{c}5.7 \\
56.9 \\
37.4\end{array}$ & $\begin{array}{c}49 \\
497 \\
471\end{array}$ & $\begin{array}{c}4.8 \\
48.9 \\
46.3\end{array}$ & $\begin{array}{c}467 \\
1544 \\
1092\end{array}$ & $\begin{array}{l}15.0 \\
49.8 \\
35.2\end{array}$ & $<0.0001$ \\
\hline $\begin{array}{l}\text { Marital status } \\
\text { Single/live alone } \\
\text { Married/ living with partner }\end{array}$ & $\begin{array}{l}435 \\
997\end{array}$ & $\begin{array}{l}30.4 \\
69.6\end{array}$ & $\begin{array}{l}141 \\
543\end{array}$ & $\begin{array}{l}20.6 \\
79.4\end{array}$ & $\begin{array}{l}423 \\
594\end{array}$ & $\begin{array}{l}41.6 \\
58.4\end{array}$ & $\begin{array}{c}999 \\
2133\end{array}$ & $\begin{array}{l}31.9 \\
68.1\end{array}$ & $<0.0001$ \\
\hline $\begin{array}{l}\text { Employment status } \\
\text { Employed } \\
\text { Student } \\
\text { Unemployed } \\
\text { Retired } \\
\text { At home }\end{array}$ & $\begin{array}{c}925 \\
91 \\
33 \\
176 \\
178\end{array}$ & $\begin{array}{c}65.9 \\
6.5 \\
2.4 \\
12.5 \\
12.7\end{array}$ & $\begin{array}{c}317 \\
14 \\
33 \\
291 \\
19\end{array}$ & $\begin{array}{c}47.0 \\
2.1 \\
4.9 \\
43.2 \\
2.8\end{array}$ & $\begin{array}{c}681 \\
49 \\
78 \\
141 \\
36\end{array}$ & $\begin{array}{c}69.1 \\
5.0 \\
7.9 \\
14.3 \\
3.7\end{array}$ & $\begin{array}{r}1923 \\
154 \\
144 \\
608 \\
233\end{array}$ & $\begin{array}{c}62.8 \\
5.0 \\
4.7 \\
19.9 \\
7.6\end{array}$ & $<0.0001$ \\
\hline $\begin{array}{l}\text { Resource perception } \\
\text { Difficult } \\
\text { Easy }\end{array}$ & $\begin{array}{c}282 \\
1073\end{array}$ & $\begin{array}{l}20.8 \\
79.2\end{array}$ & $\begin{array}{l}123 \\
557\end{array}$ & $\begin{array}{l}18.1 \\
81.9\end{array}$ & $\begin{array}{l}235 \\
778\end{array}$ & $\begin{array}{l}23.2 \\
76.8\end{array}$ & $\begin{array}{c}640 \\
2408\end{array}$ & $\begin{array}{l}21.0 \\
79.0\end{array}$ & 0.040 \\
\hline \multicolumn{10}{|c|}{ Health status and lifestyle factors } \\
\hline $\begin{array}{l}\text { Weight status } \\
\qquad 25 \mathrm{~kg} / \mathrm{m}^{2} \\
25-29.9 \mathrm{~kg} / \mathrm{m}^{2} \\
>30 \mathrm{~kg} / \mathrm{m}^{2}\end{array}$ & $\begin{array}{l}623 \\
483 \\
325\end{array}$ & $\begin{array}{l}43.5 \\
33.8 \\
22.7\end{array}$ & $\begin{array}{l}298 \\
246 \\
137\end{array}$ & $\begin{array}{l}43.8 \\
36.1 \\
20.1\end{array}$ & $\begin{array}{l}489 \\
341 \\
186\end{array}$ & $\begin{array}{l}48.1 \\
33.6 \\
18.3\end{array}$ & $\begin{array}{l}1410 \\
1070 \\
648\end{array}$ & $\begin{array}{l}45.1 \\
34.2 \\
20.7\end{array}$ & 0.044 \\
\hline $\begin{array}{c}\text { Morbidity score, } £ \\
0 \text { risk factor } \\
1 \text { risk factor } \\
2 \text { risk factors } \\
3 \text { risk factors }\end{array}$ & $\begin{array}{c}308 \\
612 \\
427 \\
51\end{array}$ & $\begin{array}{c}22.0 \\
43.8 \\
30.5 \\
3.6\end{array}$ & $\begin{array}{c}47 \\
382 \\
206 \\
26\end{array}$ & $\begin{array}{c}7.1 \\
57.8 \\
31.2 \\
3.9\end{array}$ & $\begin{array}{c}266 \\
417 \\
258 \\
51\end{array}$ & $\begin{array}{c}26.8 \\
42.0 \\
26.0 \\
5.1\end{array}$ & $\begin{array}{c}621 \\
1411 \\
891 \\
128\end{array}$ & $\begin{array}{c}20.4 \\
46.2 \\
29.2 \\
4.2\end{array}$ & $<0.0001$ \\
\hline $\begin{array}{l}\text { Smoking status } \\
\text { Never } \\
\text { Former } \\
\text { Occasional } \\
\text { Regular }\end{array}$ & $\begin{array}{c}757 \\
368 \\
46 \\
261\end{array}$ & $\begin{array}{c}52.9 \\
25.7 \\
3.2 \\
18.2\end{array}$ & $\begin{array}{c}340 \\
238 \\
25 \\
81\end{array}$ & $\begin{array}{c}49.7 \\
34.8 \\
3.7 \\
11.8\end{array}$ & $\begin{array}{c}519 \\
245 \\
54 \\
199\end{array}$ & $\begin{array}{c}51.0 \\
24.1 \\
5.3 \\
19.6\end{array}$ & $\begin{array}{l}1616 \\
851 \\
125 \\
541\end{array}$ & $\begin{array}{c}51.6 \\
27.2 \\
4.0 \\
17.3\end{array}$ & $<0.0001$ \\
\hline \multicolumn{10}{|c|}{ Health perception } \\
\hline $\begin{array}{l}\text { Self-perceived health } \\
\text { Good } \\
\text { Fair } \\
\text { Poor } \\
\text { Self-perceived health }\end{array}$ & $\begin{array}{c}878 \\
464 \\
56\end{array}$ & $\begin{array}{c}62.8 \\
33.2 \\
4.0\end{array}$ & $\begin{array}{c}533 \\
139 \\
11\end{array}$ & $\begin{array}{c}78.0 \\
20.4 \\
1.6\end{array}$ & $\begin{array}{c}731 \\
256 \\
26\end{array}$ & $\begin{array}{c}72.2 \\
25.3 \\
2.6\end{array}$ & $\begin{array}{c}2142 \\
859 \\
93\end{array}$ & $\begin{array}{c}69.2 \\
27.8 \\
3.0\end{array}$ & $<0.0001$ \\
\hline $\begin{array}{l}\text { Good } \\
\text { Fair } \\
\text { Poor }\end{array}$ & $\begin{array}{c}878 \\
464 \\
56\end{array}$ & $\begin{array}{c}62.8 \\
33.2 \\
4.0\end{array}$ & $\begin{array}{c}533 \\
139 \\
11\end{array}$ & $\begin{array}{c}78.0 \\
20.4 \\
1.6\end{array}$ & $\begin{array}{c}731 \\
256 \\
26\end{array}$ & $\begin{array}{c}72.2 \\
25.3 \\
2.6\end{array}$ & $\begin{array}{c}2142 \\
859 \\
93\end{array}$ & $\begin{array}{c}69.2 \\
27.8 \\
3.0\end{array}$ & \\
\hline $\begin{array}{l}\text { Importance of PA for health } \\
\text { Great importance } \\
\text { Enough importance } \\
\text { Little or no importance }\end{array}$ & $\begin{array}{l}556 \\
571 \\
303\end{array}$ & $\begin{array}{l}38.9 \\
39.9 \\
21.2\end{array}$ & $\begin{array}{c}253 \\
350 \\
79\end{array}$ & $\begin{array}{l}37.1 \\
51.3 \\
11.6\end{array}$ & $\begin{array}{l}370 \\
471 \\
175\end{array}$ & $\begin{array}{l}36.4 \\
46.4 \\
17.2\end{array}$ & $\begin{array}{r}1179 \\
1392 \\
557\end{array}$ & $\begin{array}{l}37.7 \\
44.5 \\
17.8\end{array}$ & $<0.0001$ \\
\hline Compliance to PA recommendations & 1120 & 81.99 & 424 & 73.99 & 623 & 71.04 & 2167 & 76.95 & $<0.0001$ \\
\hline
\end{tabular}

PA, physical activity. *Note that the total number of cases differs due to missing data on some variables; P value indicates the comparison between the 3 regions. $£$ Morbidity score includes three major cardiovascular risk factors: diabetes, hypertension or dyslipidaemia. Participants were classified as diabetics if they reported taking anti-diabetic medications and/or had fasting plasma glucose $\geq 126 \mathrm{mg} / \mathrm{dL}{ }^{22}$ Participants were classified as having elevated blood pressure if they reported taking anti-hypertensive medications and/or had SBP $\geq 140 \mathrm{mmHg}$ and/or DBP $\geq 90 \mathrm{mmHg} .{ }^{23}$ Subjects with dyslipidaemia were defined as having at least one of the following anomalies: total cholesterol $\geq 190 \mathrm{mg} / \mathrm{dL}$, triglycerides $\geq 150 \mathrm{mg} / \mathrm{dL}$, LDL-cholesterol $\geq 115 \mathrm{mg} / \mathrm{dL}$, and HDL-cholesterol $<40 \mathrm{mg} / \mathrm{dL}$ for men and $<46 \mathrm{mg} / \mathrm{dL}$ for women, and/or taking hypo-lipid medications. ${ }^{24}$ 
Table 2. Demographic, socio-economic, behavioural and health-related determinants of subjects meeting the physical activity recommendations in the Greater Region, 2007-2012.

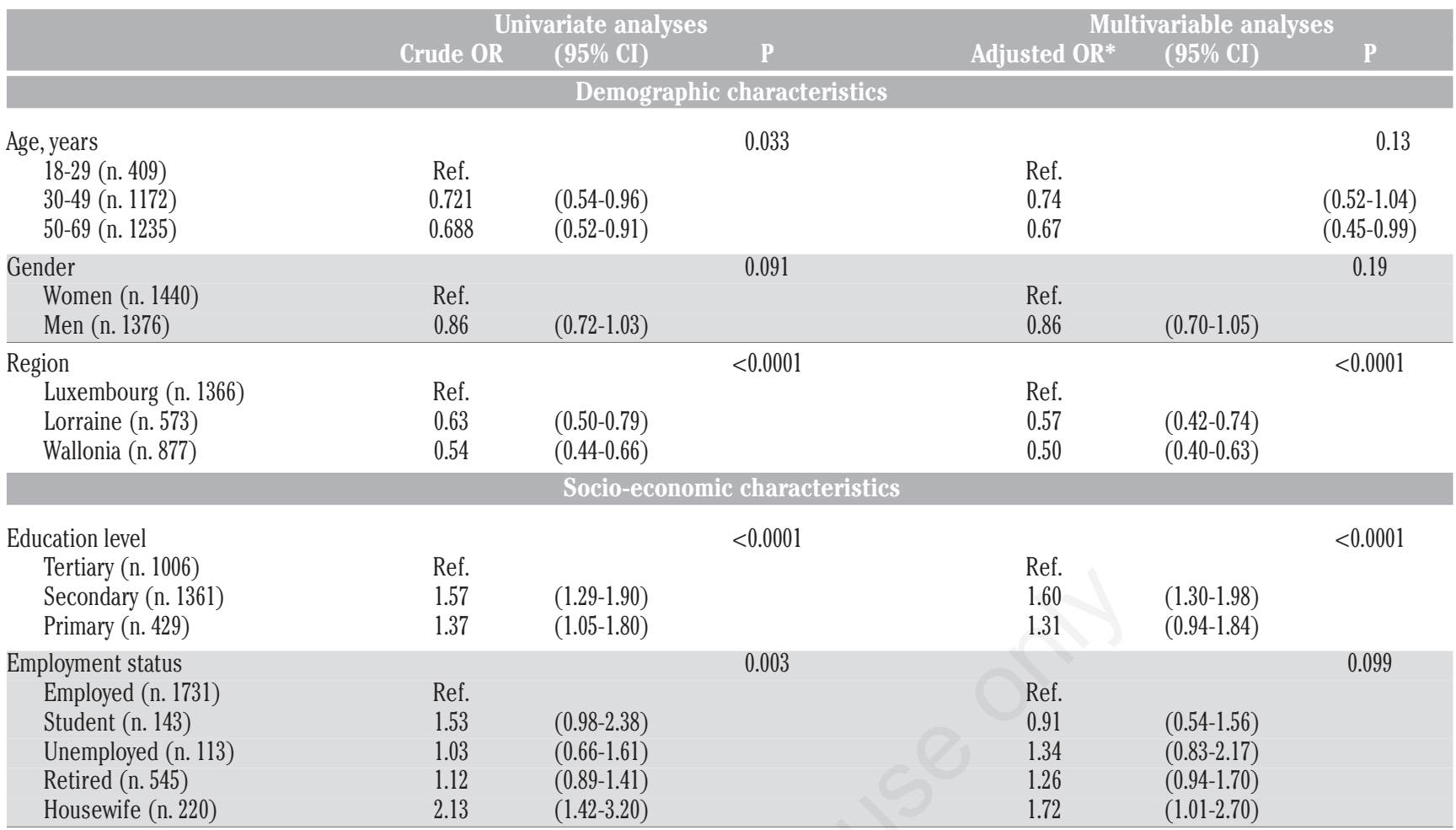

Easy (n. 2177)

Difficult (n. 561)

Ref.

0.60

$1.06 \quad(0.85-1.33)$

Health status and lifestyle factors

Marital status

Married/living with partner (n. 1923) Ref.

Single/ live alone (n. 892) $\quad 0.94 \quad$ (0.78-1.13)
BMI, $\mathrm{kg} / \mathrm{m}^{2}$

Normal weight (n. 1281)

Overweight (n. 953)

Obesity (n. 577)

Morbidity score $£$

0 risk factor

1 risk factor

2 risk factors

3 risk factors

Smoking status

Never (n. 1469)

Former (n. 772)

Occasional (n. 117)

Regular (n. 458)
Ref.

0.937

0.685

Ref.

0.93

0.96

0.56

Ref.

1.03

1.49

1.04
0.003

$$
\begin{aligned}
& (0.77-1.15) \\
& (0.55-0.86)
\end{aligned}
$$

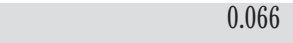

(0.74-1.18)

$0.74-1.28)$

(0.36-0.87)

(0.84-1.26)

(0.91-2.45)

(0.81-1.33)

0.47
0.48

Health perception

Self-perceived health Good (n. 1932)

Fair (n. 762)

Poor (n. 87)

Ref.

0.76

0.42

Importance of physical activity on health Great importance (n. 1064)

Enough importance (n. 1249)

Little importance (n. 501)

Ref.

0.58

0.45
$<0.0001$

$(0.63-0.92)$

$(0.27-0.65)$

$<0.0001$

$(0.47-0.71)$

(0.35-0.57)
Ref.

$1.05 \quad(0.83-1.33)$

$0.76 \quad(0.58-1.00)$

Ref.

1.04

1.16

0.95

$(0.80-1.35)$

$(0.84-1.61)$

(0.55-1.64)
0.054
0.70

$\mathrm{OR}$, odds ratio; $\mathrm{CI}$, confidence interval. Only variables showing $\mathrm{P}<0.1$ in the univariate analyses were introduced in the multivariable logistic regression model. The gaps in the table indicate that these variables (resources perception, marital status and smoking) were not introduced in the adjusted model. *OR adjusted for age, gender, region, education level, employment status, BMI, morbidity score, self-perceived health and importance of physical activity on health. \& Morbidity score includes three major cardiovascular risk factors: diabetes, hypertension or dyslipidaemia. Participants were classified as diabetics if they reported taking anti-diabetic medications and/or had fasting plasma glucose $\geq 126 \mathrm{mg} / \mathrm{dL}$. ${ }^{22}$ Participants were classified as having elevated blood pressure if they reported taking anti-hypertensive medications and/or had SBP $\geq 140$ $\mathrm{mmHg}$ and/or DBP $\geq 90 \mathrm{mmHg} .{ }^{23}$ Subjects with dyslipidaemia were defined as having at least one of the following anomalies: total cholesterol $\geq 190 \mathrm{mg} / \mathrm{dL}$, triglycerides $\geq 150 \mathrm{mg} / \mathrm{dL}$, LDL-cholesterol $\geq 115 \mathrm{mg} / \mathrm{dL}$, and HDL-cholesterol $<40 \mathrm{mg} / \mathrm{dL}$ for men and $<46 \mathrm{mg} / \mathrm{dL}$ for women, and/or taking hypo-lipid medications. ${ }^{24}$ 
physical activity. ${ }^{25}$ To date, no data have evidenced and directly compared the prevalence of adherence to physical activity recommendations among the residents of the Greater Region, encompassing Luxembourg, Lorraine and Wallonia. This information is however crucial for decision-makers and health professionals to implement effective synergistic prevention strategies, tackling high-risk groups. The outcome may have a medium to long term impact on the global health of the Greater Region population, in terms of prevention and health care policies as well as on the future economy.

\section{Meeting recommend levels of physical activity}

The present cross-border study demonstrated that more than three quarters of the Greater Region sample are meeting the recommendations, i.e. they perform at least 30 minutes of moderately intense physical activity, or 20 minutes of high intense physical activity on most days of the week. The physical activity compliance rate was $82 \%$ in Luxembourg, followed by Lorraine (74\%) and Wallonia (71\%). The European Eurobarometer survey, compared the level of physical activity among different European countries by using the IPAQ, reported slightly lower prevalence rates; about $74 \%$ of the Luxembourgish, $57 \%$ of the French and $60 \%$ of the Belgian population adhere to the WHO physical activity recommendations. ${ }^{12}$ An international comparative study, measuring physical activity with the IPAQ in 20 countries worldwide, found $57 \%$ adherence rates in Belgium, which is slightly lower than our findings for Wallonia. ${ }^{26}$ A French study, measured physical activity with the Modifiable Activity Questionnaire (MAQ), reported an adherence rate of $62 \%$ for men and $52 \%$ for women. ${ }^{27}$ This variation might be related to a difference in the practice of physical activity between regional and national level, especially in Lorraine, which displays a rather small part of France. Application of different measurement tools may also explain the inconsistent findings. Further, the time frame for recalling physical activity could also influence the results. While the IPAQ asks for physical activity during the preceding week to avoid recall bias, other studies take a longer recalling period, and refer to the last twelve months. ${ }^{9,27}$ Nevertheless, it should be considered that some of previous studies dated back a decade ago. The results from the present study may suggest an actual increase in physical activity compliance, as awareness of the benefit of exercise possibly increased through intensive public efforts.

\section{Factors associated with meeting the physical activity recommendations}

In the present study, age, gender, resources perception, employment, marital status weight status and morbidity were not related to meeting physical activity requirements, suggesting that these factors have no significant impact on the adherence to physical activity among the residents of the Greater Region. This lack of association was also observed in a study using the METh/week score as the outcome of interest. ${ }^{9}$ The present study indicated that education level was an important determinant of compliance to physical activity in our studied interregional population. Subjects with secondary education were almost twice as likely to be active and meet physical activity recommendations compared to those with tertiary education, in the multivariate model considering the employment status. Therefore, it is less probable that those with secondary education might be more engaged in manual labour, whereas those with university education might be more often performing intellectual and sedentary tasks that involve little or no physical activity during working hours. Among women, being a housewife was considerably more likely to be active and thus conform to the physical activity recommendation than the employed, probably due to the daily involvement in heavy domestic duties. Therefore, it is important to foster physical activity among sedentary occupations; the workplace can generally be a good starting point for interventions as people spend a con- siderable amount of time at work. ${ }^{28-31}$

A large proportion of the people in the three regions perceived physical activity as important to health and this was translated by their adherence to the recommended level of physical activity. ${ }^{32,33}$ Similar findings were reported by an American study of a positive relationship between leisure time physical activity and the perceived importance of physical exercise. ${ }^{34}$ Investigating self-perceived health with respect to meeting physical activity requirements, our study indicated that people with poor or fair health perception were less likely to be physically active, compared to good-health perceived subjects. Other studies have also evidenced that higher physical activity was related to better selfhealth perception. ${ }^{35,36}$ This relationship may be reciprocal; poor selfperceived health can be the result of not being sufficiently physically active and physical inability to be active may prevent the subject from being happy and feel well. Physical activity of any kind is supportive to health, and the adequate level of physical activity depends on the level of personal fitness. Anyone can be active at his own tailored physical fitness level, and consequently his own perceived health and wellbeing. Therefore, it is relevant to give adequate information to the public on the various forms of affordable physical activity, which could easily be integrated into their everyday life, rather than focussing efforts on high-cost leisure activities.

Interestingly, the present study demonstrated that the region was a significant determinant factor for meeting the physical activity recommendations; resident people in Lorraine and Wallonia were less likely to meet physical activity recommendations compared to those in Luxembourg. A possible explanation could be that sports and physical activity facilities differ between the three regions, hence influencing physical activity level to be higher in one region (Luxembourg) than the others. The findings of Eurobarometer study would support this hypothesis, as $64 \%$ of Luxembourgers strongly agree that the area where they live offers opportunities to be physically active, compared to $49 \%$ of Belgian and $51 \%$ of French respondents. ${ }^{37}$ In addition, different political and public health interventions on promoting physical activity could also lead to disparities between the regions. Again from Eurobarometer study, 75\% of respondents from Luxembourg disagreed that their local authority does not do enough for their citizens in relation to physical activity compared to $63 \%$ Belgian and $67 \%$ French respondents. ${ }^{37}$

Physical activity provides great health benefits, decreasing all-cause mortality, cardiovascular diseases, cancer, as well as improving mental health and quality of life. To increase adherence to physical activity recommendations, and stimulate better health promotion for the population of the Greater Region, there is a need for a cross-border holistic physical activity strategy, involving decision-makers and stakeholders to work together to inform adults about the importance of physical activity and to provide them with structures and facilities allowing for sustainable engagement, with a special focus on the subgroup at risk.

The present study entails some limitations. First, similar to most nationwide population-based studies, data have been retrieved via a self-administered questionnaire. Subjects generally tend to overestimate their physical activity level and may give socially desirable answers. ${ }^{38}$ Though the IPAQ has been tested for validity and reliability to measure physical activity, ${ }^{11,15,16}$ the self-reported data might have led to overrated levels of physical activity. Second, generalization of findings to the whole Grand Region population should be considered with caution, as older age groups were over represented in Lorraine and Luxembourg samples. Third, the study cannot determine a cause-effect relationship, as data were collected in a cross-sectional manner. Finally, though the study provided an extensive number of potential influencing factors, it is possible that other unexplored factors have a role in determining differences in physical activity between the three populations, such as occupational or cultural differences.

The strength of this study was the recent and homogeneous design 
of data collection including three large randomly selected samples from three neighbour regions. We performed age and gender data standardization to European population to permit meaningful cross-regional comparability. As previous international data were mainly collected on the country level, NESCaV is the first cross-regional comparative study demonstrating that the level of physical activity may differ substantially between regional and national scales.

\section{Conclusions}

In conclusion, the majority of the resident population of the Greater Region met the physical activity recommendations. Region, education level, self-health perception and subject's awareness of the importance to practice exercises and sport emerged as independent factors associated with adherence to physical activity recommendations. This study suggests awareness of the positive health effects of physical activity might be crucial for motivating the people to become more active.

Correspondence: Ala'a Alkerwi, Luxembourg Institute of Health (L.I.H), Centre de Recherche Public-Santé (formerly), Centre d'Etudes en Santé, 1A rue Thomas Edison, L-1445 Strassen, Luxembourg.

Tel.: +352.26.970.743 - Fax: +352.26 .970 .717 .

E-mail: alaa.alkerwi@crp-sante.lu; alaa.alkerwi@lih.lu

Key words: physical activity, cardiovascular risk factors, greater region, cross-border comparison.

Acknowledgments: The cross-border NESCAV project is supported by INTERREG IV A program Greater Region, 2007-2013. The regions receive a co-funding from the European Regional Development Fund (ERDF), in addition to their own or public health authorities financial support. The NESCaV Study Group thanks Marie-Lise Lair for NESCaV project coordination, as well as all the physicians, nurses, and other personnel at the investigation centres in which the surveys were carried out. Special thank goes to the participants from the three regions.

Contributions: AAlk was involved in the conception, statistical analyses and redrafting of the manuscript; BS was involved in the conception and performed the statistical analyses, and first drafting of the manuscript; NS contributed to data standardization. AAlk, FZ, and MG are the regional survey's leaders of Luxembourg, Lorraine and Wallonia, respectively. AAlb, A0 and CL contributed to the critical revision of the manuscript.

Conflict of interest: the authors declare no potential conflict of interest.

Received for publication: 7 October 2014.

Accepted for publication: 21 January 2015.

(C) Copyright A. Alkerwi et al., 2015

Licensee PAGEPress, Italy

Journal of Public Health Research 2015;4:406

doi:10.4081/jphr.2015.406

This work is licensed under a Creative Commons Attribution NonCommercial 3.0 License (CC BY-NC 3.0).

\section{References}

1. Sofi F, Capalbo A, Cesari F, et al. Physical activity during leisure time and primary prevention of coronary heart disease: an updated meta-analysis of cohort studies. Eur J Cardiovasc Prev Rehabil 2008;15:247-57.

2. Slattery ML. Physical activity and colorectal cancer. Sports Med 2004;34:239-52.

3. Glenister D. Exercise and mental health: a review. J R Soc Health
1996;116:7-13.

4. Laforge RG, Rossi JS, Prochaska J0, et al. Stage of regular exercise and health-related quality of life. Prev Med 1999;28:349-60.

5. Warburton DE, Charlesworth S, Ivey A, et al. A systematic review of the evidence for Canada's physical activity guidelines for adults. Int J Behav Nutr Phys Act 2010;7:39.

6. Bull F, Armstrong TP, Dixon T, eds. Comparative quantification of health risks: a global and regional burden of disease attributable to selected major risk factors. Geneva: WHO; 2004.

7. Waxman A. WHO global strategy on diet, physical activity and health. Food Nutr Bull 2004;25:292-302.

8. WHO. Global health risks: mortality and burden of disease attributable to selected major risks. Available from: http://www.who.int/healthinfo/global_burden_disease/GlobalHealt hRisks_report_full.pdf.

9. Martinez-Gonzalez MA, Varo JJ, Santos JL, et al. Prevalence of physical activity during leisure time in the European Union. Med Sci Sports Exerc 2001;33:1142-6.

10. Rutten A, Abu-Omar K. Prevalence of physical activity in the European Union. Soz Praventivmed 2004;49:281-9.

11. Rutten A, Vuillemin A, Ooijendijk WT, et al. Physical activity monitoring in Europe. The European Physical Activity Surveillance System (EUPASS) approach and indicator testing. Public Health Nutr 2003;6:377-84.

12. Sjöström M, Oja P, Hagströmer M, et al. Health-enhancing physical activity across European Union countries: the Eurobarometer study. J Publ Health 2006;14:291-300.

13. Alkerwi A, Guillaume M, Zannad F, et al. Nutrition, environment and cardiovascular health (NESCAV): protocol of an inter-regional cross-sectional study. BMC Public Health 2010;10:698.

14. Alkerwi A, Sauvageot N, Donneau AF, et al. First nationwide survey on cardiovascular risk factors in Grand-Duchy of Luxembourg (ORISCAV-LUX). BMC Public Health 2010;10:468.

15. Craig CL, Marshall AL, Sjostrom M, et al. International physical activity questionnaire: 12-country reliability and validity. Med Sci Sports Exerc 2003;35:1381-95.

16. Rutten A, Ziemainz H, Schena F, et al. Using different physical activity measurements in eight European countries. Results of the European Physical Activity Surveillance System (EUPASS) time series survey. Public Health Nutr 2003;6:371-6.

17. IPAQ group. Guidelines for data processing and analysis of the International Physical Activity Questionnaire (IPAQ) - short and long forms. Available from: https://sites.google.com /site/theipaq/questionnaire_links

18. Sjöström M, Ainsworth BE, Bauman A, et al. Guidelines for data processing and analysis of the International Physical Activity Questionnaire (IPAQ). Stockholm: Karolinka Institute; 2005.

19. WHO. Global recommendations for physical activity on health. Geneva: WHO; 2010.

20. WHO. Obesity: preventing and managing the global epidemic. Report of a WHO consultation. Geneva: WHO; 2010.

21. Ahmad OA, Boschi-Pinto C, Lopez AD, et al. Age standardization of rates: a new WHO standard. 2001. Available frm: http://www.who.int/healthinfo/paper31.pdf

22. Ryden L, Standl E, Bartnik M, et al. [Guidelines on diabetes, prediabetes, and cardiovascular diseases]. Rev Esp Cardiol 2007;60:1e-64e. [Article in Spanish].

23. Mancia G, De Backer G, Dominiczak A, et al. 2007 Guidelines for the management of arterial hypertension: the task force for the management of arterial hypertension of the European Society of Hypertension (ESH) and of the European Society of Cardiology (ESC). Eur Heart J 2007;28:1462-536.

24. De Backer G, Ambrosioni E, Borch-Johnsen K, et al. European guidelines on cardiovascular disease prevention in clinical prac- 
tice. Third Joint Task Force of European and Other Societies on Cardiovascular Disease Prevention in Clinical Practice. Eur Heart J 2003;24:1601-10.

25. WHO. Physical activity and health in Europe: evidence for action. 2006. Available frm: http://www.euro.who.int/_data/assets/pdf_file/0011/87545/E89490 .pdf

26. Bauman A, Bull F, Chey T, et al. The international prevalence study on physical activity: results from 20 countries. Int J Behav Nutr Phys Act 2009;6:21.

27. Bertrais S, Preziosi P, Mennen L, et al. Sociodemographic and geographic correlates of meeting current recommendations for physical activity in middle-aged French adults: the Supplementation en Vitamines et Mineraux Antioxydants (SUVIMAX) study. Am J Public Health 2004;94:1560-6.

28. Vaz de Almeida MD, Graca P, Afonso C, et al. Physical activity levels and body weight in a nationally representative sample in the European Union. Public Health Nutr 1999;2:105-13.

29. Macera CA, Ham SA, Yore MM, et al. Prevalence of physical activity in the United States: behavioral risk factor surveillance system, 2001. Prev Chronic Dis 2005;2:A17.

30. Salmon J, Owen N, Bauman A, et al. Leisure-time, occupational, and household physical activity among professional, skilled, and less-skilled workers and homemakers. Prev Med. 2000;30:191-9.

31. Marcus BH, Williams DM, Dubbert PM, et al. Physical activity intervention studies: what we know and what we need to know: a scientific statement from the American Heart Association Council on nutrition, physical activity, and metabolism (Subcommittee on
Physical Activity); Council on Cardiovascular Disease in the Young; and the Interdisciplinary Working Group on Quality of Care and Outcomes Research. Circulation 2006;114:2739-52.

32. Perk J, De Backer G, Gohlke H, et al. European guidelines on cardiovascular disease prevention in clinical practice (version 2012). The fifth joint task force of the European Society of Cardiology and other societies on cardiovascular disease prevention in clinical practice (constituted by representatives of nine societies and by invited experts). Eur Heart J 2012;33:1635-701.

33. Zethelius B, Gudbjornsdottir S, Eliasson B, et al. Level of physical activity associated with risk of cardiovascular diseases and mortality in patients with type-2 diabetes: report from the Swedish National Diabetes Register. Eur J Prev Cardiol 2014;21:244-51.

34. Laffrey SC, Isenberg M. The relationship of internal locus of control, value placed on health, perceived importance of exercise, and participation in physical activity during leisure. Int J Nurs Stud 2003;40:453-9.

35. Sodergren M, Sundquist J, Johansson SE, Sundquist K. Physical activity, exercise and self-rated health: a population-based study from Sweden. BMC Public Health 2008;8:352.

36. Abu-Omar K, Rutten A, Robine JM. Self-rated health and physical activity in the European Union. Soz Praventivmed 2004;49:235-42.

37. Eurobarometer. Sport and Physical Activity. Brussels: European Commission; 2010.

38. Lee PH, Macfarlane DJ, Lam TH, Stewart SM. Validity of the international physical activity questionnaire short form (IPAQ-SF): a systematic review. Int J Behav Nutr Phys Act 2011;8:115. 